\title{
MANIFESTAÇÕES PATOLÓGICAS EM PAREDES DE CONCRETO MOLDADAS IN LOCO: ESTUDO DE CASO
}

\author{
A. C. LORDSLEEM JR., V. Q. LIRA \\ Departamento de Engenharia Civil, Escola Politécnica, Universidade de Pernambuco, Recife, Brasil.

\section{RESUMO}

O principal programa de habitação popular do Brasil entregou 54\% das moradias com falhas, onde se destaca o sistema parede de concreto em 52\% das edificações. Este trabalho objetiva identificar e analisar as manifestações patológicas que ocorrem nas vedações verticais do sistema parede de concreto. A metodologia contemplou a realização de 2 estudos de caso, através da inspeção predial, análise dos problemas, compilação das características e recomendações de reparo. Os resultados apontaram 23 tipos de manifestações patológicas, ocorrências predominantes de fissuras e manchas de umidade, origem preponderante nas etapas de projeto e execução e anomalias como endógenas. Como contribuição, presume-se que a identificação, caracterização e os reparos promovam a correção das manifestações e permitam previnir casos semelhantes.

Palavras clave: Vedações verticais inovadoras; Parede de concreto; Manifestações patológicas. 


\section{INTRODUÇÃO}

A utilização de novas tecnologias na construção civil tem como objetivo aumentar a produtividade nas escalas de projeto, empresa e indústria, reduzindo o tempo de construção e o desperdício.

Em especial, os usos de vedações verticais inovadoras em comparação com a construção tradicional demonstram vantagens significativas, como a melhoria da qualidade, redução do tempo de construção (20\%), resíduos de construção (56\%), poeira e ruído no local e necessidade de mãodeobra $(9,5 \%)$ (JAINLOM, POON e CHIANG, 2009; WAGHMARE e VAISHALI, 2015).

Uma das tecnologias construtivas inovadoras que vêm sendo empregadas na construção civil brasileira (BONIN, AMORIM, 2006; ECKER, MARTINS, 2014; CBIC, 2016; ALMEIDA, 2018), com o intuito de enfrentar o déficit habitacional e promover racionalidade e produtividade é o sistema parede de concreto moldado in loco.

O sistema parede de concreto é uma tecnologia de construção industrializada e racionalizada que visa a melhoria da produtividade, velocidade, baixo custo e qualidade, indicado para construções com alta repetitividade (CORSINI, 2011; THIYAGARAJAN; ANNERSELVAM; NAGAMANI, 2017).

De acordo com a Associação Brasileira de Cimento Portland (ABCP, 2008), o uso do sistema parede de concreto no Brasil remonta experiências consagradas nas décadas de 70 e 80, com tipologias de construção industrializadas em concreto celular (sistema Gethal) e em concreto convencional (sistema Outinord), além do uso de fôrmas deslizantes e trepantes. Devido algumas limitações, entre outras, do sistema financeiro de habitação na época, tais tipologias foram refreadas quanto à consolidação no mercado brasileiro.

Segundo Abreu (2019), somente com o crescimento da economia brasileira (2006-2014), o ambiente se tornou propício para a aplicação do sistema parede de concreto, tendo em vista as vantagens para construções em larga escala e de baixo custo. Desde então, consolidou-se na maioria dos empreendimentos, o emprego do sistema parede de concreto com o uso de fôrmas de alumínio.

De maneira geral, o período recente de desenvolvimento da economia do Brasil e o aquecimento do mercado da construção civil também trouxeram consigo o aumento da ocorrência de manifestações patológicas.

O principal programa de habitação popular brasileiro Minha Casa Minha Vida (MCMV) entregou 54\% das moradias com manifestações patológicas, segundo levantamento realizado pela ControladoriaGeral da União (CGU) em parceria com o Ministério da Transparência em 77 empreendimentos e 1.472 unidades habitacionais em doze estados do país (BRASIL, 2017).

O MCMV foi responsável por parcela expressiva das inovações tecnológicas introduzidas nas vedações verticais brasileiras nesta última década, onde se destaca o emprego do sistema parede de concreto em $52 \%$ das unidades construídas (SANTOS, 2016).

Apesar da importancia, ainda são restritas as pesquisas que descrevem e analisam as manifestações patológicas do sistema parede de concreto (ABDUL-RAHMAN et al., 2014; MIOTTO, 2014; VIEIRA, 2014; LIRA, 2019).

Dentro do contexto apresentado, o presente trabalho tem como foco a identificação e descrição das manifestações patológicas que ocorrem em sistemas de vedação vertical inovadores, em particular, o sistema parede de concreto mais recentemente utilizado em obras dos estados de Pernambuco e Alagoas, na região nordeste do Brasil.

\section{OBJETIVO}

Este trabalho tem como objetivo principal identificar e analisar as manifestações patológicas que ocorrem nas vedações verticais do sistema parede de concreto utilizados em empreendimentos nos estados de Pernambuco e Alagoas, na região nordeste do Brasil. 


\section{PESQUISA DE ESTUDO DE CASO}

\subsection{Metodología}

A pesquisa realizada neste trabalho é um estudo de múltiplos casos com abordagem qualitativa. As seguintes etapas sistematizam o fluxo de realização desta pesquisa de estudo de casos, as quais são descritas na sequência: seleção dos empreendimentos utilizados como alvo do estudo, caracterização dos empreendimentos escolhidos, dimensionamento das amostras em cada empreendimento, procedimento de inspeção predial, e por fim, compilação e análise dos resultados.

Em relação à seleção dos empreendimentos estudados, Gil (2008) aponta que a escolha do objeto de estudo pode não ser exclusivamente determinada pela sua relevância, mas também pela facilidade de acesso. Com base em tal critério, a escolha dos empreendimentos escolhidos para realização da pesquisa se deu a partir da permissão de acesso aos empreendimentos, por parte de seus gestores (síndico, presidente de associação de moradores e morador).

Após identificados os empreendimentos com sistema parede de concreto, entrou-se em contato com os síndicos, cuja autorização permitiu a realização da pesquisa em dois conjuntos habitacionais, sendo um em cada estado, Alagoas e Pernambuco.

Em relação à caracterização dos empreendimentos escolhidos, foi realizada ao passo que os gestores autorizavam a utilização dos empreendimentos como objeto do estudo de caso da pesquisa. Esta etapa teve como objetivo a identificação das características dos empreendimentos, tais como localização, configuração geométrica das unidades habitacionais, quantidade de unidades habitacionais, data de início e término da construção, sistemas construtivos e materiais utilizados, funcionamento da manutenção das edificações, adaptação dos usuários aos sistemas construtivos, entre outras. As informações obtidas para essa caracterização utilizaram as seguintes fontes de evidencias: entrevistas, análise de projetos, análise de documentos e observação direta.

Em relação ao dimensionamento das amostras em cada empreendimento, o critério utilizado para seleção do número de unidades a serem vistoriadas foi baseadono consentimento do gestor do empreendimento e do morador.No caso do Empreendimento A, um conjunto habitacional no estado de Alagoas, o consentimento partiu do presidente da associação de moradores, que permitiu abordar cada umadas unidades habitacionais, solicitando permissão para avaliar cada casa. A segunda permissão partia do próprio morador, permitindo ou não a entrada na residência. No Empreendimento B, o gestor foi o síndico da edificação, que permitiu que a equipe avaliasse as unidades habitacionais que ainda não tinham sido entregues pela construtora, e ainda se encontravam desocupadas. A partir desse momento, a autorização partiu da equipe do pós-obra da construtora, permitindo a entrada em algumas unidades. Em relação à inspeção predial, buscou-se efetuar a avaliação sistêmica da edificação, com intuito de classificar as não-conformidades constatadas quanto a sua origem, grau de risco e indicar orientações técnicas necessárias à melhoria da manutenção dos sistemas e elementos construtivos.A inspeção realizada seguiu o procedimento estabelecido pelo IBAPE (Instituto Brasileiro de Avaliação e Perícias em Engenharia), através da Norma de Inspeção Predial Nacional (IBAPE, 2012).

A inspeção predial conforme o procedimento do IBAPE (2012) contemplou as seguintes etapas:

- Definição do nível da inspeção predial: classifica a mesma quanto a sua complexidade, considerando as características técnicas da edificação, manutenção e operação existentes. Os níveis de inspeção predial podem ser classificados em nível 1, nível 2 e nível 3. A inspeção empreendimento A foi classificada como nível 1 (baixa complexidade do empreendimento e inexistência de plano de manutenção); enquanto, no empreendimento B foi classificada como nível 2 (edificação de média complexidade técnica de manutenção e operação de seus elementos e sistemas construtivos, com mais de um pavimento, com plano de manutenção, além de empresas terceirizadas contratadas para execução de atividades específicas como manutenção de bombas, portões, reservatórios de água, dentre outros); 
- Análise da documentação: possibilitou o conhecimento prévio das características da edificação que foram encontradas na vistoria. Foram fornecidos nessa etapa os projetos arquitetônicos dos empreendimentos, essenciais para realização da vistoria, além controle tecnológico do concreto utilizado na concretagem das paredes;

- Elaboração do checklist: formulário destinado à anotação das constatações técnicas e dos resultados encontrados na vistoria. Buscou facilitar o levantamento dos dados no campo, a partir do planejamento da vistoria, bem como o arquivamento das informações encontradas, servindo como prova física do nível de qualidade da inspeção realizada. O checklist teve como base as manifestações patológicas que foram discutidas na revisão bibliográfica;

- Entrevistas: buscou compreender o contexto em que estão inseridas as manifestações patológicas encontradas. Através das entrevistas iniciais com os gestores foi possível caracterizar as edificações. Os entrevistados no empreendimento A foram o presidente da associação de moradores do conjunto habitacional em Alagoas e o engenheiro responsável pela assistência técnica no pós-obra e moradores das casas e, no empreendimento B, foram o engenheiro responsável pela assistência técnica no pós-obra, engenheiro que acompanhou a obra e síndico do prédio;

- Realização de vistorias: foram observadas as manifestações patológicas encontradas nas vedações verticais das unidades habitacionais. Nessa etapa, ocorreu o acesso às residências, registrando no checklist todas as ocorrências encontradas.

Em relação à compilação e análise de resultados, buscou-se reunir os dados coletados apresentando as informações considerando os seguintes parâmetros: percentual de ocorrência das manifestações patológicas em cada empreendimento, quantidade de manifestações patológicas por unidade habitacional, frequência das manifestações patológicas encontradas, caracterização e recomendações de reparos.

Cada uma das principais manifestações patológicas identificadas é organizada na forma de quadro, permitindo descrever sucintamente o sintoma, mecanismo, causa, origem, classificação e recomendações.

A seguir, a compilação e análise dos resultados são apresesentados.

\section{RESULTADOS}

O estudo de caso contemplou os 2 empreendimentos ilustrados nas Figuras 1 e 2 construídos com as vedações verticais no sistema parede de concreto moldado in loco.

O Quadro 1 elenca as principais características dos empreendimentos.

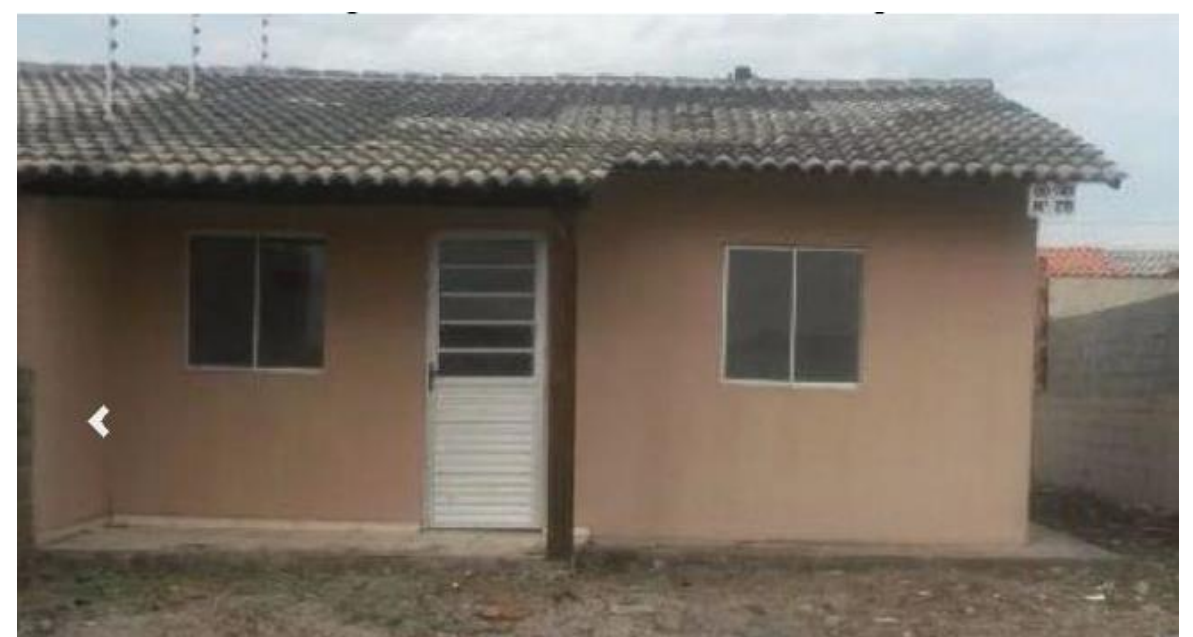

Figura 1. Conjunto habitacional de casas do empreendimento A 


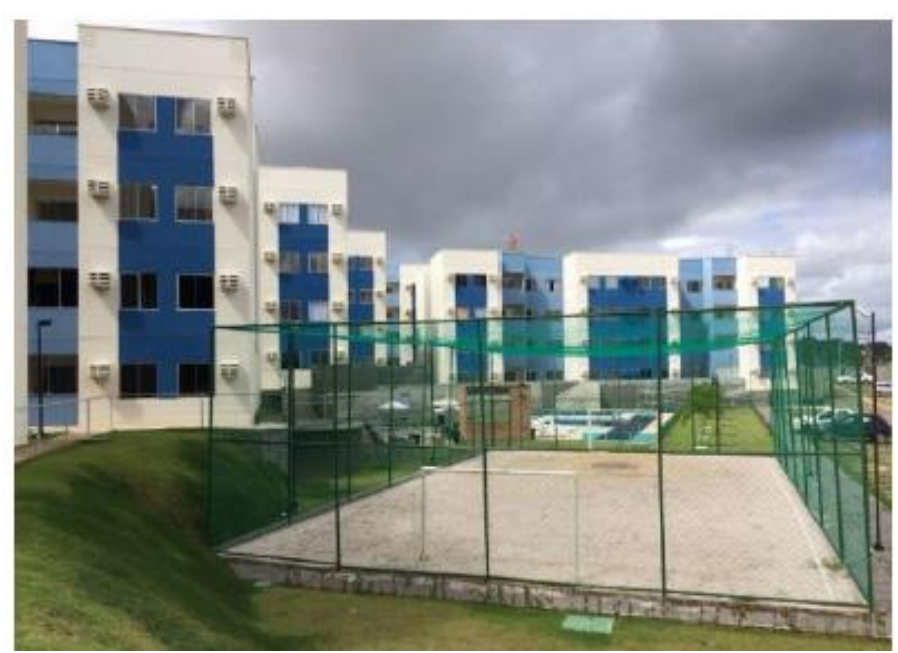

Figura 1. Conjunto habitacional de edifícios de apartamentos do empreendimento B

Quadro 1. Caracterização dos empreendimentos analisados no estudo de caso

\begin{tabular}{|c|c|c|}
\hline \multicolumn{3}{|c|}{ Caracterização dos empreendimentos } \\
\hline & Empreendimento A & Empreendimento B \\
\hline Localização & Alagoas (Brasil) & Pernambuco (Brasil) \\
\hline Tipologia & $\begin{array}{c}\text { Conjunto habitacional de } \\
\text { casas }\left(52 \mathrm{~m}^{2}\right)\end{array}$ & $\begin{array}{c}\text { Conjunto habitacional de } \\
\text { apartamentos }\left(42 \mathrm{~m}^{2} \mathrm{e} 44 \mathrm{~m}^{2}\right)\end{array}$ \\
\hline $\begin{array}{c}\text { Quantidade de unidades } \\
\text { habitacioanais }\end{array}$ & 460 casas & 10 blocos -320 apartamentos \\
\hline Concreto utilizado nas paredes & $\begin{array}{c}\text { Concreto celular espumoso } \\
-4 \mathrm{MPa}\end{array}$ & $\begin{array}{c}\text { Concreto - } 25 \mathrm{Mpa} \\
\text { Aditivo plastificante - Fibra de } \\
\text { polipropileno }\end{array}$ \\
\hline Armação utilizada nas paredes & $\begin{array}{c}\text { Tela soldada - } 15 \times 15 \mathrm{~cm}- \\
\varnothing 4,2 \mathrm{~mm}\end{array}$ & $\begin{array}{c}\text { Tela soldada }-15 \times 15 \mathrm{~cm}-\varnothing 4,2 \\
\mathrm{~mm}\end{array}$ \\
\hline Reforços nas armações & $\begin{array}{l}\text { Reforço nas aberturas de } \\
\text { portas e janelas }(6,3 \mathrm{~mm})\end{array}$ & $\begin{array}{c}\text { Reforço nas aberturas de portas e } \\
\text { janelas }(8 \mathrm{~mm}) \text { e no encontro } \\
\text { entre paredes (tela) }\end{array}$ \\
\hline Idade & 4 anos & 1 ano \\
\hline
\end{tabular}

No empreendimento A constituído por 460 unidades habitacionais do tipo casa de concreto celular foram vistoriadas 26 casas, distribuídas nas 18 quadras do terreno. As vistorias foram efetuadas em 3 dias de visita.

No empreendimento B constituído por 320 apartamentos em 10 blocos foram vistoriados 25 apartamentos. As vistorias ocorreram em 2 dias de visita.

Após o agrupamento dos dados dos dois empreendimentos foi possível obter um panorama geral das manifestações patológicas encontradas nas paredes de concreto moldadas in loco. $\mathrm{O}$

Quadro 2reúne um resumo geral das manifestações encontradas nos dois empreendimentos.

Observa-se que somente três tipos de manifestações patológicas foram comuns aos dois empreendimentos (fissuras nas aberturas de portas e janelas, fissuras no meio das paredes e fissuras no encontro entre paredes). Todas as outras manifestações patológicas aconteceram de forma isolada em apenas um dos empreendimentos.

A peculiaridade dos tipos de manifestações patológicas em cada um dos empreendimentos permite considerarque a ocorrência das mesmas deve estar associada as características particulares de cada empreendimento (projetos, materiais, mão de obra, localização) e não necessariamente ao sistema de 
vedação vertical parede de concreto moldada in loco, visto que, apesar da utilização de um sistema com características semelhantes, a maioria das manifestações identificadas foram diferentes.

Destaca-se o fato de que todas as unidades habitacionais inspecionadas, em ambos os empreendimentos, apresentaram pelo menos uma manifestação patológica. A quantidade média de manifestações patológicas por unidade habitacional, em cada um dos empreendimentos, pode ser observada no Quadro 3. Em relação as ocorrências de manifestações patológicas nas unidades habitacionais, destaca-se que a média quantitativa foi próxima, tendo 4,8 ocorrências de manifestações por unidade habitacional no empreendimento A e 4,2 ocorrências por unidade habitacional no empreendimento B. Os valores são considerados altos, e longe do que se espera no que tange a qualidade das edificações.

Quadro 2. Percentual de ocorrência das manifestações patológicas

\begin{tabular}{|c|c|c|c|c|}
\hline \multirow{3}{*}{ Manifestação patológica } & \multicolumn{4}{|c|}{ Empreendimento } \\
\hline & \multicolumn{2}{|c|}{$\mathbf{A}$} & \multicolumn{2}{|c|}{ B } \\
\hline & $\begin{array}{c}\mathrm{N}^{0} \text { de } \\
\text { ocorrências }\end{array}$ & $\%$ & $\begin{array}{c}\mathbf{N}^{0} \text { de } \\
\text { ocorrências }\end{array}$ & $\%$ \\
\hline Fissuras nas aberturas de portas e janelas & 20 & $16 \%$ & 6 & $6 \%$ \\
\hline Fissuras no meio das paredes & 15 & $12 \%$ & 4 & $4 \%$ \\
\hline Fissuras no encontro entre paredes & 8 & $6 \%$ & 1 & $1 \%$ \\
\hline $\begin{array}{l}\text { Mancha de umidade junto ao piso em paredes } \\
\text { externas }\end{array}$ & 29 & $23 \%$ & 0 & $0 \%$ \\
\hline Fissuras no topo das paredes, próximo a coberta & 12 & $10 \%$ & 0 & $0 \%$ \\
\hline Fissuras junto ao piso em paredes externas & 10 & $8 \%$ & 0 & $0 \%$ \\
\hline $\begin{array}{l}\text { Mancha de umidade em paredes com } \\
\text { instalações hidráulicas }\end{array}$ & 8 & $6 \%$ & 0 & $0 \%$ \\
\hline Portas e esquadrias de madeira danificadas & 7 & $6 \%$ & 0 & $0 \%$ \\
\hline $\begin{array}{c}\text { Mancha de umidade no topo das paredes, } \\
\text { próximo a coberta }\end{array}$ & 5 & $4 \%$ & 0 & $0 \%$ \\
\hline $\begin{array}{l}\text { Fissuras em áreas que sofreram intervenção dos } \\
\text { usuários }\end{array}$ & 4 & $3 \%$ & 0 & $0 \%$ \\
\hline Desagregação do revestimento argamassado & 4 & $3 \%$ & 0 & $0 \%$ \\
\hline $\begin{array}{l}\text { Fissuras na ligação de paredes de concreto com } \\
\text { paredes de alvenaria }\end{array}$ & 3 & $2 \%$ & 0 & $0 \%$ \\
\hline Fissuras ao redor da caixa de ar condicionado & 0 & $0 \%$ & 30 & $28 \%$ \\
\hline $\begin{array}{l}\text { Fissuras na parte inferior das esquadrias de } \\
\text { alumínio }\end{array}$ & 0 & $0 \%$ & 22 & $21 \%$ \\
\hline $\begin{array}{c}\text { Manchas de umidade ao redor das esquadrias } \\
\text { em paredes internas }\end{array}$ & 0 & $0 \%$ & 13 & $12 \%$ \\
\hline Falhas na pintura & 0 & $0 \%$ & 10 & $9 \%$ \\
\hline Pequenos furos no revestimento & 0 & $0 \%$ & 8 & $8 \%$ \\
\hline Manchas retangulares nas paredes & 0 & $0 \%$ & 6 & $6 \%$ \\
\hline Fissuras grandes no meio das paredes & 0 & $0 \%$ & 2 & $2 \%$ \\
\hline
\end{tabular}




\begin{tabular}{|c|c|c|c|c|}
\hline \multirow{3}{*}{ Manifestação patológica } & \multicolumn{4}{|c|}{ Empreendimento } \\
\hline & \multicolumn{2}{|c|}{$\mathbf{A}$} & \multicolumn{2}{|c|}{$\mathbf{B}$} \\
\hline & $\begin{array}{c}\mathbf{N}^{\mathbf{o}} \text { de } \\
\text { ocorrências }\end{array}$ & $\%$ & $\begin{array}{c}\mathrm{N}^{\mathbf{0}} \text { de } \\
\text { ocorrências }\end{array}$ & $\%$ \\
\hline $\begin{array}{l}\text { Manchas de umidade pontuais no meio das } \\
\text { paredes }\end{array}$ & 0 & $0 \%$ & 2 & $2 \%$ \\
\hline Bolor ao redor das esquadrias & 0 & $0 \%$ & 1 & $1 \%$ \\
\hline Descolamento da cerâmica & 0 & $0 \%$ & 1 & $1 \%$ \\
\hline Manchas de umidade nas fachadas externas & 0 & $0 \%$ & & \\
\hline Total & 125 & $100,00 \%$ & 106 & $100,00 \%$ \\
\hline
\end{tabular}

Fonte: Autores (2019)

Quadro 3. Quantidade de manifestação patológica por unidade habitacional

\begin{tabular}{|c|c|c|}
\cline { 2 - 3 } \multicolumn{1}{c|}{} & Empreendimento A & Empreendimento B \\
\hline $\mathrm{N}^{\circ}$ de unidades habitacionais inspecionadas & 26 & 25 \\
\hline $\mathrm{N}^{\circ}$ de ocorrências identificadas & 125 & 106 \\
\hline Manifestações patológicas/unidades habitacionais & 4,8 & 4,2 \\
\hline
\end{tabular}

Fonte: Autores (2019)

Apesar da grande variedade de manifestações patológicas encontradas em ambos empreendimentos, suas representatividades são bem diferentes. Para os dois casos, três tipos de manifestações patológicas concentram mais da metade das ocorrências identificadas.

No empreendimento A, as três principais ocorrências foram: mancha de umidade junto ao piso em paredes externas, fissuras nas aberturas de portas e janelas e fissuras no meio das paredes.De modo que juntas representaram 64 das 125 ocorrências, isto é, 51\% das manifestações patológicas encontradas.

A Figura 3, apresenta a frequência de todas as manifestações patológicas encontradas no empreendimento A, destacando a frequência das três primeiras, que impactam significativamente na qualidade do empreendimento.
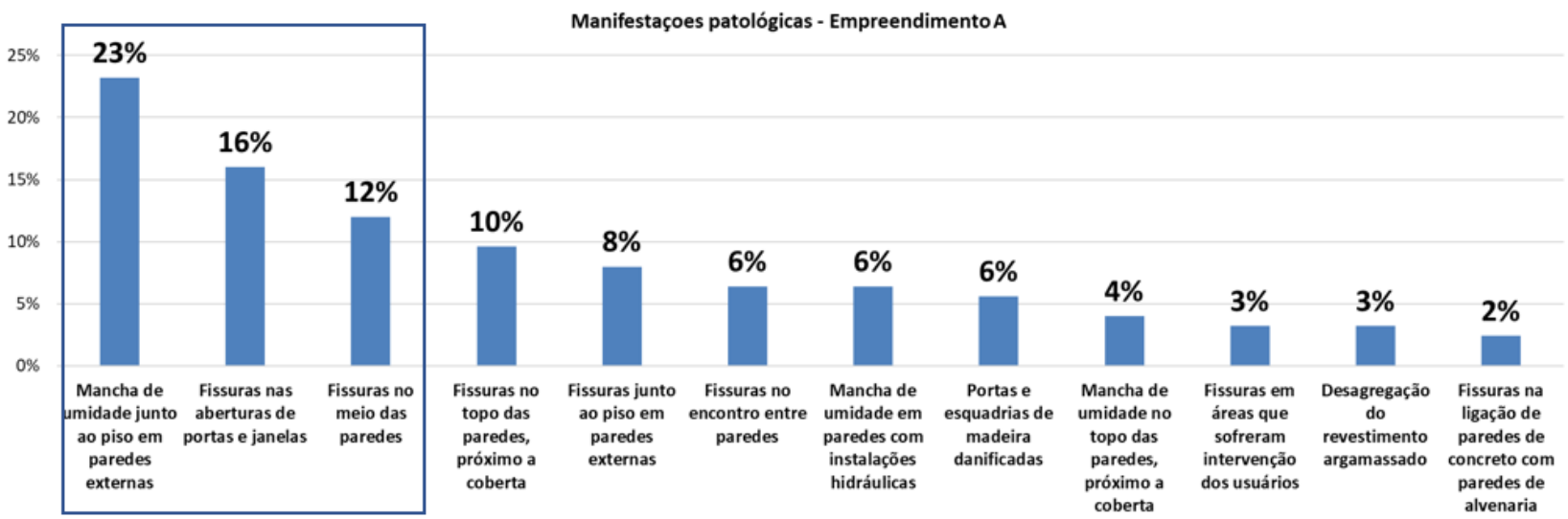

Figura 3. Gráfico de frequência das manifestações patológicas no empreendimento A

Fonte: Autores (2019) 
No empreendimento B a situação é semelhante, as três principais manifestações patológicas foram: fissuras ao redor da caixa de ar condicionado, fissuras na parte inferior das esquadrias de alumínio e manchas de umidade ao redor das esquadrias em paredes internas. Juntas representaram 65 das 106 ocorrências, isto é, $61 \%$ das manifestações patológicas encontradas.

A Figura 4 apresenta o gráfico que mostra a representatividade dessas manifestações patológicas, em comparação as outras manifestações identificadas.

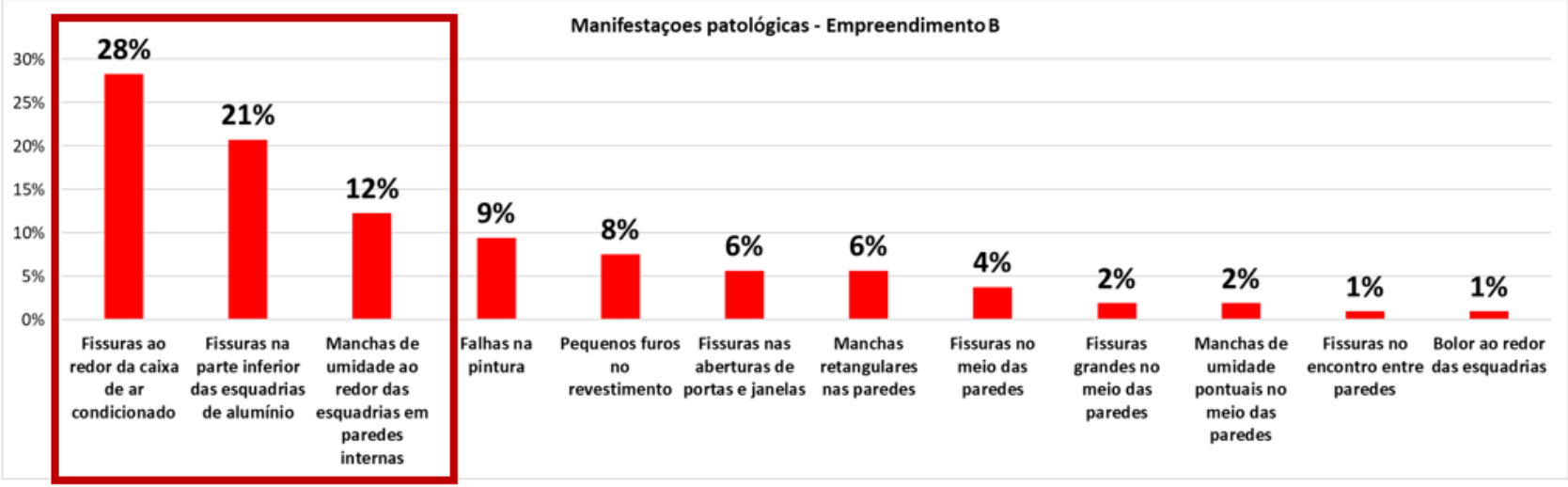

Figura 4. Gráfico de frequência das manifestações patológicas no empreendimento B

Fonte: Autores (2019)

Os Quadros 4, 5, 6, 7, 8 e 9 caracterizam e apresentam as recomendações de reparo para as principais manifestações patológicas identificadas nos dois empreendimentos.

Quadro 4. Caracterização de manchas de umidade junto ao piso em paredes externas

\begin{tabular}{|c|c|}
\hline \multicolumn{2}{|c|}{ Mancha de umidade, bolor e mofo junto ao piso em paredes externas } \\
\hline \multicolumn{2}{|c|}{ Ocorência no empreendimento A: $23 \%$} \\
\hline & \\
\hline & \\
\hline Sintoma & Manchas de umidade, bolor e mofo próximas ao piso nas paredes externas \\
\hline Mecanismo & Ciclos de molhagem e secagem da água da chuva \\
\hline Causa & $\begin{array}{l}\text { Comprimento insuficiente do beiral da coberta/Ausência de manutenção } \\
\text { periódica do revestimento da fachada }\end{array}$ \\
\hline Origem & Projeto arquitetônico/Manutenção \\
\hline Classificação & Anomalia endógena/Falha de planejamento \\
\hline Recomendações & Lavagem da área manchada/Reparo do revestimento \\
\hline
\end{tabular}

Fonte: Autores (2019) 
Quadro 5. Caracterização das fissuras nas aberturas de portas e janelas

\section{Fissuras nas aberturas de portas e janelas}

\begin{tabular}{|c|l|}
\hline Ocorrência no empreendimento A: $16 \%$ & Ocorrência no empreendimento B: $6 \%$ \\
\hline & \\
\hline Sintoma & Fissuras ao redor de aberturas de portas e janelas em paredes de concreto. \\
\hline Mecanismo provável & Acúmulo de tensões de tração nas aberturas. \\
\hline Causa provável & Armadura de reforço insuficiente \\
\hline Origem provavel & Projeto estrutural/Execução da armadura de reforço \\
\hline Classificação & Anomalia endógena \\
\hline Recomendações & Reforço da armadura ao redor das aberturas \\
\hline
\end{tabular}

Fonte: Autores (2019)

Quadro 6. Caracterização de fissuras no meio das paredes

\begin{tabular}{|c|l|}
\hline \multicolumn{2}{|c|}{ Fissuras no meio das paredes } \\
\hline Ocorrência no empreendimento A: $12 \%$ & Ocorrência no empreendimento B: 4\% \\
\hline & \\
& \\
\hline Sintoma & Aparecimento de fissuras ao longo das paredes de concreto \\
\hline Causa provável & Ocorrência de tensões de tração ao longo das paredes \\
\hline Origem & Execução do concreto \\
\hline Classificação & Anomalia endógena \\
\hline Recomendações & Demolir superficialmente área fissurada e refazê-la \\
\hline
\end{tabular}

Fonte: Autores (2019) 
Quadro 7. Caracterização de fissuras ao redor da caixa de ar condicionado

\section{Fissuras ao redor da caixa de ar condicionado}

\begin{tabular}{|c|l|}
\hline \multicolumn{3}{|c|}{ Ocorrência no empreendimento B: $28 \%$} \\
\hline \\
\\
\hline Sintoma & Aparecimento de fissuras ao redor das caixas de ar condicionado \\
\hline Mecanismo provável & $\begin{array}{l}\text { Acúmulo de tensões na interface de fixação entre a parede e a caixa do ar } \\
\text { condicionado }\end{array}$ \\
\hline Causa provável & Retração da argamassa de fixação \\
\hline Origem & Escolha dos materiais \\
\hline Classificação & Anomalia endógena \\
\hline Recomendações & Substituição do material de fixação da caixa de ar-condicionado na parede \\
\hline
\end{tabular}

Fonte: Autores (2019)

Quadro 8. Caracterização das fissuras na parte inferior das esquadrias de alumínio

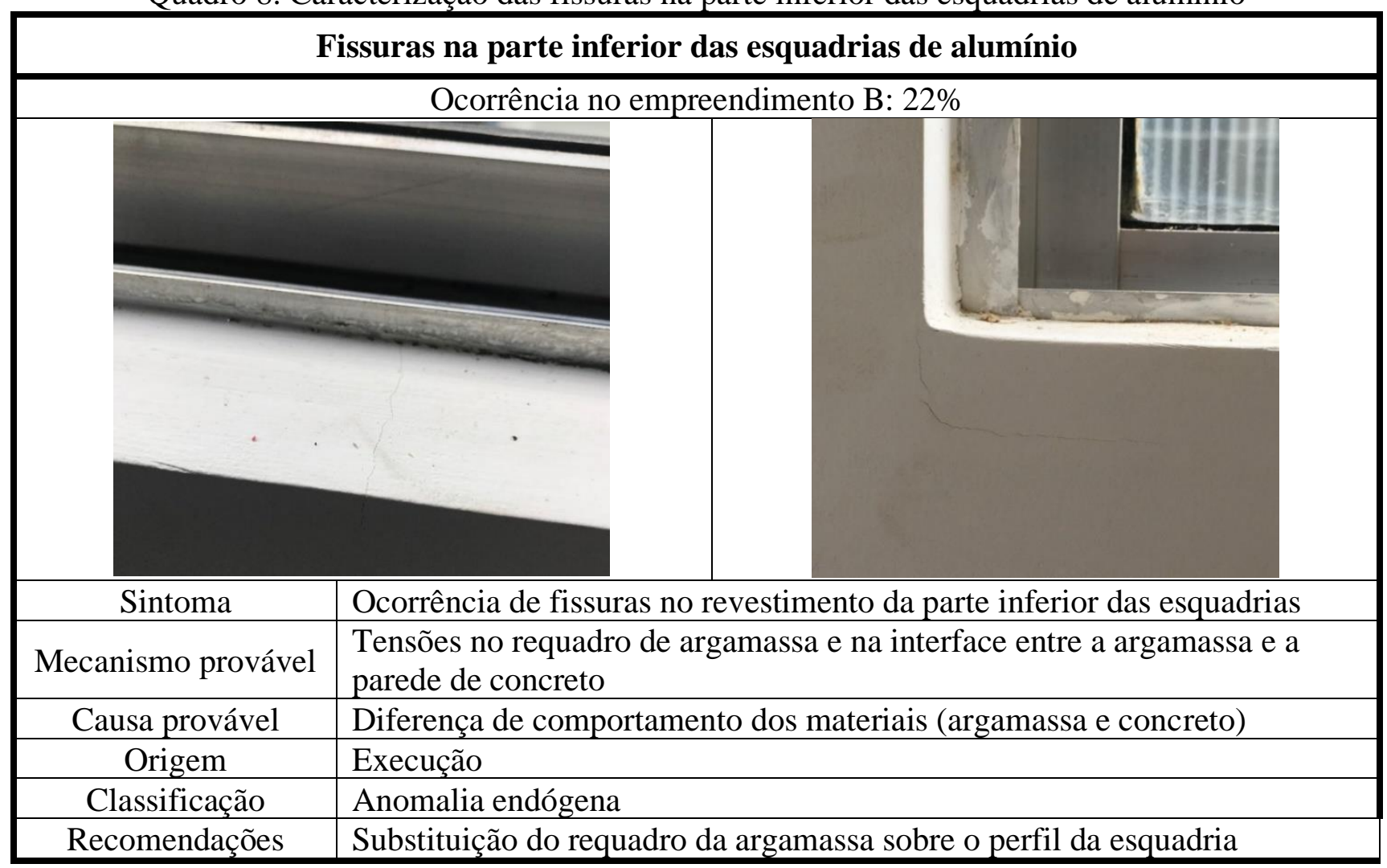

Fonte: Autores (2019) 
Quadro 9. Caracterização das manchas de umidade ao redor das esquadrias em paredes internas

\begin{tabular}{|c|l|}
\hline \multicolumn{2}{|c|}{ Manchas de umidade ao redor das esquadrias em paredes internas } \\
\hline & \\
\hline
\end{tabular}

Fonte: Autores (2019)

Através da caracterização das manifestações patológicas pode-se chegar a conclusões em relação as origens e causas que levaram a ocorrências desses mecanismos de degradação, de modo a promover seu reparo e evitar que voltem a acontecer.

\section{CONCLUSÕES}

Os dois empreendimentos estudados identificaram juntos 23 tipos de manifestações patológicas, das quais apenas 3 se repetiram nos dois empreendimentos, todas as outras foram exclusivas de cada um dos empreendimentos A ou B. Esse fato indica que a maioria das manifestações patológicas estão associadas as características de projeto, execução, materiais e manutenção, não estando necessariamente associadas ao sistema de vedação em parede de concreto. Isto é, a adoção de melhores práticas, por parte das construtoras, é o principal fator para diminuir a ocorrência dessas manifestações patológicas.

Nos dois empreendimentos foi identificado um mesmo padrão de comportamento: as três manifestações patológicas de maior frequência são responsáveis por mais da metade das ocorrências identificadas. Ratificando o fato de que um procedimento de execução inadequado pode promover uma grande quantidade de replicação da mesma manifestação patológica, afetando no desempenho da edificação.

De uma forma geral, o grupo de maior representatividade nas manifestações patológicas encontradas foram as fissuras, que obtiveram $57 \%$ de ocorrências no empreendimento A e $62 \%$ de ocorrência no empreendimento B. Logo após as fissuras vieram as machas de umidade, caracterizadas por 33\% das manifestações no empreendimento A e $15 \%$ das manifestações no empreendimento B. Constatando o que foi encontrado na revisão bibliográfica, que já indicavam essas manifestações patológicas como as principais nos sistemas de parede de concreto moldadas in loco. 
Por fim, percebe-se no contexto da pesquisa que o sistema parede de concreto está sendo consolidado no mercado da construção civil brasileira; porém, as empresas ainda estão se adaptando em relação as melhores práticas de execução.

\section{REFERÊNCIAS}

Associação Brasileira de Cimento Portland - ABCP (2008), "Parede de Concreto - Coletânea de ativos 2007/2008". São Paulo: ABCP, 2008.

Abdul Kadir, M. R. et al. (2006), Construction performance comparison between conventional and industrialized building systems in Malaysia. Structural Survey, 24(5):412-424.

Abreu, M. M. (2019), "Atividades da mão de obra que mais influenciam na produtividade do sistema parede de concreto", Dissertação (Mestrado) - Escola Politécnica, Universidade de Pernambuco. Recife, p. 130.

Almeida, H. R. (2018), “Inovações tecnológicas em edificações habitacionais: avaliação pós-ocupação das vedações verticais", Dissertação (Mestrado) - Escola Politécnica, Universidade de Pernambuco. Recife, p. 96.

Bonin, L. C., Amorim, S. R. L. (2006), "Inovação tecnológica na construção habitacional”. Porto Alegre: ANTAC, 2006.

Brasil (2017), "Relatório de avaliação da execução de programa de governo $n^{\circ}$ 66. Programa Minha Casa Minha Vida - FGTS". Disponível em: < https://auditoria.cgu.gov.br/download/9775.pdf>. Acesso em 10 de dezembro de 2017.

Câmara Brasileira da Construção Civil - CBIC (2016), "Catálogo de inovação na construção civil”. Brasília: CBIC, 2016.

Corsini, R. (2011). Paredes Normatizadas. Téchne, São Paulo, 2011.

Ecker, T. W.P., Martins, V. (2014), "Comparativo dos sistemas construtivos steel frame e wood frame para habitações de interesse social”, Pato Branco, 2014. Trabalho de conclusão de curso (Graduação) - Universidade Tecnológica Federal do Paraná.

Gil, A. C. (2008), “Métodos e técnicas de pesquisa social”. São Paulo: Atlas, 2008.

Instituto Brasileiro de Avaliações e Perícias - IBAPE (2012), "Norma de Inspeção Predial Nacional",

São Paulo, 2012.

Jaillon, L.; Poon, C. S.; Chiang, Y. H. (2009), Quantifying the waste reduction potential of using prefabrication in building construction in Hong Kong. Waste Management, 29(1):309-320.

Lira, V. Q. (2019), "Manifestações patológicas em vedações verticais inovadoras: estudo de caso", Dissertação (Mestrado) - Escola Politécnica, Universidade de Pernambuco. Recife, p. 257.

Miotto, A. (2014), "Avaliação das patologias no sistema construtivo em paredes de concreto moldadas no local para edifícios residenciais", Trabalho de Conclusão de Curso (Graduação) Universidade Tecnológica Federal do Paraná. Curitiba, p. 72.

Santos, A. (2017), "Paredes de concreto já dominam minha casa minha vida". Disponível em: <http://www.cimentoitambe.com.br/paredes-de-concreto-minha-casa-minha-vida/>. Acesso em: $02 \mathrm{de}$ agosto de 2017.

Thiyagarajan, R.; Panneerselvam, V.; Nagamani, K. (2017), Aluminium formwork system in highrise buildings construction. International Journal of Advanced Research in Engineering and Technology, $8(6): 29-41$.

Vieira, L. B. (2014), "Projeto de paredes de concreto armado: apresentação das recomendações normativas e avaliação da influência das aberturas", Dissertação (Mestrado) - Escola Politécnica, Universidade Federal da Bahia, Salvador.

Waghmare, A.; Vaishali, T. A. (2015), Study of cost comparison of precast concrete vs. cast-in-place. International Multidisciplinary e-Journal, 4(11):27-34. 